\title{
Applications of artificial neural network and Box-Behnken Design for modelling malachite green dye degradation from textile effluents using $\mathrm{TiO}_{2}$ photocatalyst
}

\author{
Chandrika. K.C ${ }^{1}$, T. Niranjana Prabhu ${ }^{{ }^{\dagger}}$, R. R. Siva Kiran ${ }^{2}$, R. Hari Krishna ${ }^{3^{\dagger}}$ \\ ${ }^{1}$ Department of Chemistry, Faculty of Mathematical and Physical Sciences, M.S. Ramaiah University of Applied Sciences, Bangalore-560 058, India \\ ${ }^{2}$ Department of Chemical Engineering, M. S. Ramaiah Institute of Technology, Bangalore-560054, India \\ ${ }^{3}$ Department of Chemistry, M. S. Ramaiah Institute of Technology, Bangalore-560054, India
}

\begin{abstract}
Most of the photocatalytic studies for pollutant degradation are based on optimizing a single parameter that results in a non-linear relationship between the overall parameters and the photo-degradation reactions. To address this critical problem, herein, we report the use of Response Surface Methodology based on the Box-Behnken Design (BBD) for modeling the photocatalysis degradation of Malachite Green (MG) dye using nano $\mathrm{TiO}_{2}$ as photocatalyst. The catalyst characterizations are carried out using XRD, SEM, and TEM, indicating that the TiO 2 prepared by sol-gel synthesis possesses Anatase phase with particles in the nano regime and porous surface morphology. The optimum operating conditions for degradation of MG was identified by the interactive effects of variable factors such as initial dye concentration 10-30 ppm ( $\mathrm{x}_{1}$ ), catalyst dosage 1-3 mg $\left(\mathrm{x}_{2}\right)$, contact time 20-60 min $\left(\mathrm{x}_{3}\right)$ using the Box-Behnken method. Furthermore, the degradation reactions are also evaluated by Artificial Neural Networks (ANN). Their predicted results have been validated by the experimental studies and found to be acceptable. Their optimal results to achieve $90 \%$ degradation efficiency at $\mathrm{TiO}_{2}$ nanoparticle dosage $(3 \mathrm{mg})$, reaction time $(60$ min), and initial dye concentration (20 ppm) have been validated by the experimental studies and found to be acceptable.
\end{abstract}

Keywords: ANN, Box-Behnken, Malachite green, Photocatalysis, $\mathrm{RSM}, \mathrm{TiO}_{2}$

\section{Introduction}

Contaminants like heavy metal ions, surfactants, fertilizers, pesticides, and various toxic organic dyes by agriculture, industries, and human activities bring undesirable changes into air, water, and soil leads to environmental pollution [1]. In developing countries, growing population and industrial development demand water supply, but their activities produce a large amount of wastewater, disposed to natural water bodies without treatment causing water pollution. In recent years organic pollutants like dyes, released through wastewater from various industries into natural water bodies (to the environment), became a serious health problem. These dyes are toxic to human beings and aquatic life [2]. Malachite Green (MG) is used as a colorant in various textile industries. It is also used as a food additive, food coloring agent, medical disinfectant, and so on; it is highly carcinogenic and genotoxic.

This is an Open Access article distributed under the terms of the Creative Commons Attribution Non-Commercial License (http://creativecommons.org/licenses/by-nc/3.0/) which permits unrestricted non-commercial use, distribution, and reproduction in any medium, provided the original work is properly cited.

Copyright (C) 2022 Korean Society of Environmental Engineers
Nowadays, MG dye became a controversial pollutant due to its risk to the immune system [3]. Among various oxidation methods used, photocatalytic oxidation using semiconductor photocatalysts was found to be efficient for environmental applications like water purification and water disinfection [4]. Removal of pollutants along with mineralization can be done by photocatalysis and is more advantageous than other conventional methods [5], such as adsorption, precipitation, co-precipitation, oxidation, reduction, aerobic, anaerobic, and biological treatment methods, because of their inherent limitations like less efficiency, time consumption and the formation of secondary sludge, the disposal of the same is uneconomical.

A review of various reports suggests that the nanomaterials are efficient photocatalysts because of their smaller size and the larger surface area or because of quantum confinement effects of charge carriers for the pollutant degradation [6]. Over the last few decades,

Received October 02, 2020 Accepted January 04, 2021

${ }^{\dagger}$ Corresponding author

E-mail: niranjan1975@gmail.com, rhk.chem@msrit.edu Tel: +91-9448853894, +91 9886434109 Fax: +91-80-49065500 ORCID: 0000-0003-4939-2781 
the researcher's attention is to use nano metal oxide semiconductors for photocatalysis. Among various metal oxide semiconductor photocatalysts, $\mathrm{ZnO}$ and $\mathrm{TiO}_{2}$ have proven to be the most suitable photocatalysts. $\mathrm{TiO}_{2}$ has been popularized as a photocatalyst because of its long-term stability, high oxidative properties, and environmental friendliness. However, other semiconductor oxides and sulphide catalysts such as $\mathrm{Fe}_{2} \mathrm{O}_{3}, \mathrm{ZrO}_{2}, \mathrm{Cr}_{2} \mathrm{O}_{3}, \mathrm{ZnS}$, CdS have also used to degrade several contaminants in the presence of UV/Visible light [7]. Photocatalysis has the appeal of being "green" since it only uses light photons to eliminate toxic organic chemicals [8, 9].

Increasing literature in the field of chemistry explaining the use of Artificial Neural Networks (ANN) has evolved for a various range of applications such as Environmental Engineering, Textile Dye Degradation, Photocatalysis, Simulation and Modelling methods, Wastewater Quality Monitoring, Prediction of results (Water Quality Index), Design of reactors and many more. Because ANNs are sets of essential functions, they can deliver better empirical models of complex nonlinear processes that are advantageous for a wide variety of purposes. Pirdashti M. et al. reviewed a variety of ANN applications in chemical engineering. It dealt with the critical aspects of the ANN topology, modelling strategy, the methods of developing and training the data [10]. A systematic classification arrangement is also presented, which reveals, categorizes, and concludes the present works connected to ANN methodologies as well as applications. Theory of neural computing and its applications in the area of chemical science are reported elsewhere [11].

However, an attempt has been made to prent a quick review of the few related articles in this section. In large industrial reactor systems, corrupted data is inevitable. In such cases, different techniques can also be implemented to restructure the lost data. In this regard and in contrast to neural network modelling, Piagram et al. [12] discovered that the interpolated and moving average value methods provided the adequate estimates than the more commonly used median and mean replacement methods. From the context of analytical calibration, Miller J.N. discussed fundamental statistical approaches for analytical chemistry [13] which gives detailed information in the area of curve fitting and linear regression, which helps to understand the basics of equation modelled in this work (Eq. (2) and (5)).

It is challenging to model simulations by adopting conventional mathematical approaches as several factors influence them. Issues of simulation, Modelling and the importance of ANN as a solution are expanding because of their simplicity in Modeling of process performance, simulation and prediction [14]. Mohammadi et al. [15] used ANNs to model and predict the decolourization of dyes like methyl orange (MO) and methylene blue (MB) by $\mathrm{Sn} / \mathrm{Zn}-\mathrm{TiO}_{2}$ nanoparticles synthesized by the sol-gel method. The forecasted results of this model were found to be in good agreement with the experimental results. Response Surface Methodology was implemented using Central Composite Design for malachite green removal [16], but very few studies were done with Box-Behnken Design (BBD). The BBD offers optimal results with few experimental runs when compared with other response surface methodology techniques [17].

In the present study use of sol-gel synthesized $\mathrm{TiO}_{2}$ as photocatalyst for the malachite green degradation is explored. To over- come the drawbacks of conventional one parameter at a time approach, which is time consuming, multi parameter variation at a time has been explored by using BBD to achieve the maximum $\%$ dye degradation with few experiments. This approach also helps to understand the influence of interactive effects of the two parameters on the Photodegradation of malachite green dye by $\mathrm{TiO}_{2}$ nanoparticles. Additionally, the BBD and the ANNs techniques were validated with statistically optimized experimental results and comparison between the two techniques' ability to predict the results are discussed.

\section{Experimental}

\subsection{Sol Gel Synthesis of $\mathrm{TiO}_{2}$ Nanoparticles}

Sol-gel method is employed to synthesize $\mathrm{TiO}_{2}$ Nanoparticles (NPs). Briefly, $5 \mathrm{~mL}$ each of absolute ethanol and glacial acetic acid were mixed well. The mixture was added dropwise to $10 \mathrm{~mL}$ of titanium (iv) isopropoxide with continuous magnetic stirring for $30 \mathrm{~min}$ and left undisturbed for $5 \mathrm{~h}$. After this aging period a pale-yellow transparent gel was formed. The obtained gel was dried over-night at $70^{\circ} \mathrm{C}$ in hot air oven to form white powder. Then, the resulting powder upon grinding, an ultra-fine white powder was formed. Finally, the resulting powder was calcined at $450^{\circ} \mathrm{C}$ for $2 \mathrm{~h}$ to increase the crystallinity of the as-formed sample.

\subsection{Characterization}

The crystallite size and phase composition of synthesized $\mathrm{TiO}_{2}$ nanoparticles were determined by X-ray diffraction (Panalytical X'pert-Pro powder diffractometer). The morphological feature and microstructure of nano $\mathrm{TiO}_{2}$ were inspected by scanning electron microscopy (JEOL (JSM-840A)) and transmission electron microscopy (Hitachi $\mathrm{H}-8100\left(\mathrm{LaB}_{6}\right.$ filament, accelerating voltage up to $200 \mathrm{kV})$ ). UV Visible spectral data and band-gap energy was determined by using a UV-Visible spectrometer (Specord 250 plus, Germany). Elemental composition was detected by an energy dispersive spectrometer (EDS; Keney Sigma TM Quasar, USA)).

\subsection{Photocatalytic Experiments}

Photodegradation of malachite green dye of chemical formula $\left[\mathrm{C}_{6} \mathrm{H}_{5} \mathrm{C}\left(\mathrm{C}_{6} \mathrm{H}_{4} \mathrm{~N}\left(\mathrm{CH}_{3}\right)_{2}\right)_{2}\right] \mathrm{Cl}-4$, IUPAC name [ (4 - dimethylamino phenyl) phenyl methyl]- N.N-dimethyl aniline was carried out by using the synthesized $\mathrm{TiO}_{2}$ NPs under UV light. A stock solution (10 ppm) was prepared by dissolving malachite green in double distilled water to investigate the degradation efficiency. For each experiment, $10 \mathrm{~mL} \mathrm{MG}$ solution of $10 \mathrm{ppm}$ concentration was used by varying the parameters like initial dye concentration $(20 \mathrm{ppm}$, $30 \mathrm{ppm}$ and $40 \mathrm{ppm})$, catalyst dosage, (1 mg, $2 \mathrm{mg}, 3 \mathrm{mg}$ ), time (20 $\mathrm{min}, 40 \mathrm{~min}$ and $60 \mathrm{~min}$ ). The solution was stirred well at $300 \pm 10 \mathrm{rpm}$ under UV light of distance $10 \mathrm{~cm}$ and intensity 250 watts. All the reactions were carried out at constant temperature (2 $5 \pm 1^{\circ} \mathrm{C}$ ). After the reaction time, the supernatant liquid was taken out, and the changes in the dye concentration were evaluated by using UV-Vis spectrophotometer (Shimadzu UV-2600) by monitoring absorbance at $617 \mathrm{~nm}\left(\lambda_{\max }\right)$. The efficiency of photocatalytic degradation of MG dye was calculated by the equation: 


$$
\text { photocatalytic degradation }(\%)=\frac{C o-C}{C o} \times 100
$$

In the above equation, Co is initial dye concentration and $\mathrm{C}$ is the final dye concentration after photo degradation.

\section{Modelling Tools for Design of Experiments \& ANN}

Many researchers are using many techniques and tools for Design of Experiments such as Central Composite Design, BBD, etc., In the present work, the combination of RSM with BBD has been used. For further optimalization of RSM results Artificial Intelligence (AI) is introduced in the present study to predict the results in and around the experimental boundary.

\subsection{Modeling Using BBD}

BBD with three factors ( 3 independent variables) each at three levels $(-1,0,1)$, one dependent variable, one block with three replicates at the centre points gives 15 sets of experiments. They are used for the modelling of operational parameters for degradation of MG dye at different initial dye concentration $(10,20$ and $30 \mathrm{ppm}$ ), catalyst dosage (1,2 and $3 \mathrm{mg}$ ) and time (20, 40 and $60 \mathrm{~min}$ ). The context of design should be sufficient to fit all requirements such as one squared term, a linear term, a product of two variables and an intercept to fit a quadratic model.

To study the effect of different variables towards their responses and the subsequent optimization studies, BBD has been used. To determine the relationship between the factors and the response variables, the collected data were analyzed by the statistical manner utilizing regression. A regression design is usually employed to model the response as a mathematical function, as shown in Eq. (2):

$$
\begin{gathered}
\mathrm{Y}=\beta_{0}+\beta_{1} x_{1}+\beta_{2} x_{2}+\beta_{3} x_{3}+\beta_{11} x_{1}^{2}+\beta_{22} x_{2}^{2}+ \\
\beta_{33} x_{3}^{2}+\beta_{12} x_{1} x_{2}+\beta_{13} x_{1} x_{3}+\beta_{23} x_{2} x_{3}
\end{gathered}
$$

Response function (2nd order polynomial) was estimated by performing regression analysis, representing the linear, quadratic as well as cross-product response of variables $\mathrm{x}_{1}, \mathrm{x}_{2}, \mathrm{x}_{3}$ on response. Where $\beta_{0}, \beta_{1}, \beta_{2}, \beta_{3}$ are the coefficients estimated from regression and $\mathrm{Y}$ is the predicted dependent variable. The analysis was done using Statsoft Inc., Tulsa, USA (Version 6).

\subsection{Modelling Using ANN}

ANN is inspired by the working principle of neurons present in the human brain. ANN simulates the brain learning process by using probabilistic mathematical models. ANN operates directly on input-output data [18], and Matlab 2020b (Mathworks, USA) consists of various functions to implement artificial neural network architecture.

Neural network architecture consists of an input layer, one or more hidden layers and an output layer. The neurons in the hidden layer are linked to the input and output layers. The input data fed to neural network architecture is divided into a training set and a testing set. The most common training algorithm used to process ANN is the back-propagation algorithm. In this training algorithm, the error between the output neurons and the actual output (experimental data) of the training set were calculated and propagated backwards until it minimizes the error. After modeling the training data using ANN, the testing data set is used to verify the accuracy of the predictions and Multiple Coefficient of Regression $\left(\mathrm{R}^{2}\right)$ was calculated. The neural network model is considered as an objective function for optimization [18]. The DIRECT optimization algorithm adopted by Ravi et al. [19] was used for optimizing Malachite green degradation. TOMLAB Optimization Inc, Sweden developed the MATLAB code for implementing DIRECT Algorithm (Global Optimization Technique).

\section{Results and Discussion}

\subsection{X-ray Diffraction}

Fig. 1. Shows the X-ray diffraction pattern of nano $\mathrm{TiO}_{2}$ prepared by sol-gel method. All the diffraction peaks observed are highly crystalline and can be readily indexed to anatase phase $\mathrm{TiO}_{2}$. The diffraction peaks identified for the anatase phase is in accordance with the standard JCPDS card no. 21-1272. No other diffraction peaks other than those corresponding to $\mathrm{TiO}_{2}$ are observed indicating the phase purity of the sample prepared. The broader diffraction peaks indicate the smaller crystallite size of the catalyst. Further, the crystallite size of the sample was calculated by peak broadening calculations using Scherrer's formula

$$
D=\frac{K \lambda}{\beta \cos \theta}
$$

Where $\lambda$ is the X-Ray wavelength, $\beta$ is the full width at half maxima, $\theta$ is Bragg's angle and $\mathrm{K}$ is the shape factor (constant). Its value is 0.9 (for spherical shaped particles). The average crystallite size of $\mathrm{TiO}_{2}$ is calculated and is found to be $\sim 11 \mathrm{~nm}$. The peaks intensity confirms highly crystalline nature of $\mathrm{TiO}_{2}$.

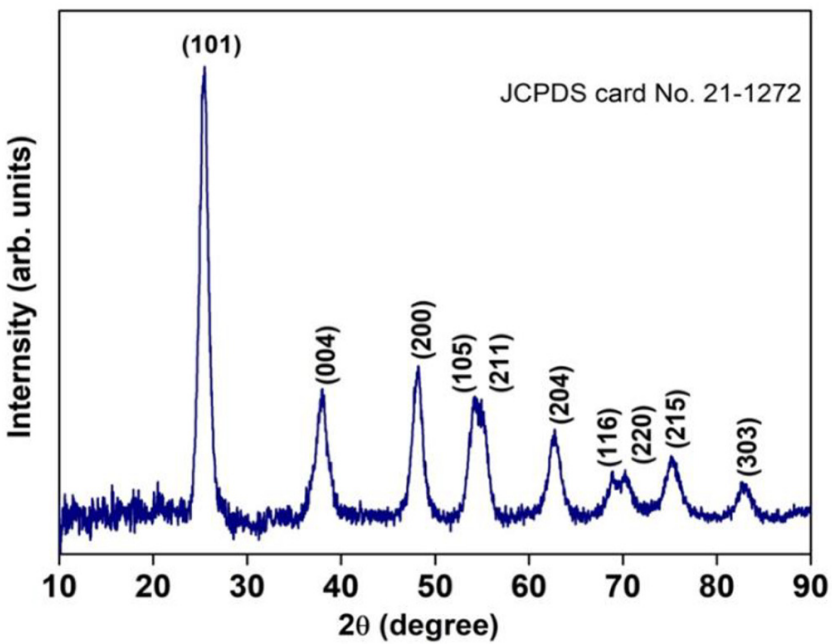

Fig. 1. PXRD of sol gel derived anatase $\mathrm{TiO}_{2}$. 


\subsection{Microstructural and Optical Characterizations}

Morphology of synthesized $\mathrm{TiO}_{2}$ nanoparticles was studied by using a scanning electron microscope (SEM), and it is shown in Fig. 2(a). The surface structure of the catalyst was found to be agglomerated mass of particles with varying size of agglomeration. Careful observation of SEM micrographs reveals the porous agglomerated clusters with fine voids on the structure. In order to evaluate the size of the particles, transmission electron micrographs are recorded and are shown in Fig. 2(b)-(c). From TEM images, it can be inferred that the particles are nearly spherical and a few particles are irregular in shape. However, irrespective of the shape of the agglomeration, the particles can be seen with particles connected to each other. Agglomerations of particles are of typical nano-sized particles in order to decrease the high surface energy. The particle size from the TEM micrographs was calculated to be in the range of 30-40 nm. Furthermore, the HR-TEM image (Fig. 2(c)) shows clear lattice fringes with well observable atomic planes. The d-spacing from the HR-TEM was calculated to be $0.356 \mathrm{~nm}$ and corresponds to (101) plane of anatase $\mathrm{TiO}_{2}$. The TEM and HR-TEM results are in accordance with the PXRD and SEM results.

UV-Visible absorption spectra of Sol-gel derived $\mathrm{TiO}_{2}$ nanoparticles are depicted in Fig. 3(a). The absorbance spectrum of the sample reveals an absorption band in the UV region ranging from 270-390 nm. Further Wood and Tauc relation (Eq. (4)) is used to determine the optical energy gap of the prepared samples.

$$
\alpha h v \propto\left(h v-E_{g}\right)^{k}
$$

Where a, h, n, $\mathrm{E}_{\mathrm{g}}$ and $\mathrm{k}$ represent the absorption coefficient, Planck's constant, frequency, optical energy band gap and constant $(k=1 / 2,2$ and $3 / 2$ for direct, indirect and direct -indirect forbidden transitions), respectively. The optical band gap of sol-gel derived $\mathrm{TiO}_{2}$ nano particles is estimated by plotting (ahn) ${ }^{2} \mathrm{Vs}$ hn (Fig. 3(b)). It can be observed from Tauc plot that the optical energy band gap value is found to be $3.1 \mathrm{eV}$ and matches with the reported values for anatase $\mathrm{TiO}_{2}$.

\section{Photocatalytic Studies}

As a preliminary study to know the approximate range of parameters (which is required for DOE) the experiments have been conducted by one parameter at a time approach. Influence of each parameter on dye degradation is discussed in section 5.1 to 5.3 and the interactive effects of the parameters (by RSM) on dye degradation are discussed in section 6.1 to 6.3 .
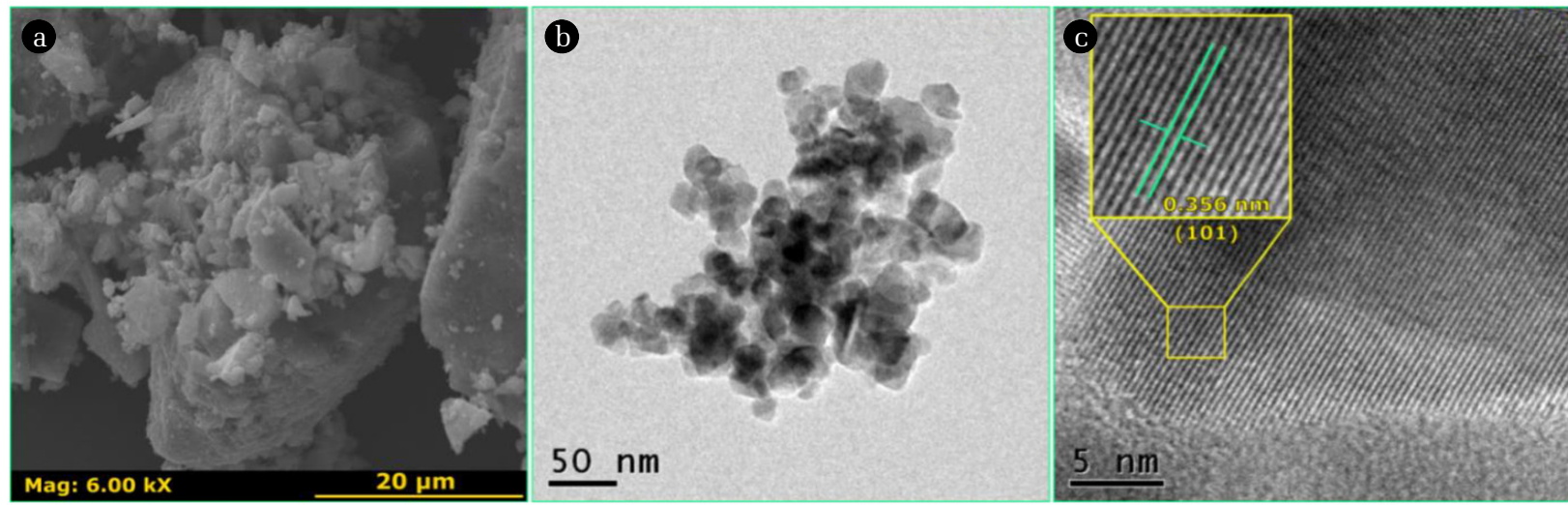

Fig. 2. (a) SEM (b) TEM and (c) HRTEM of sol gel derived $\mathrm{TiO}_{2}$.
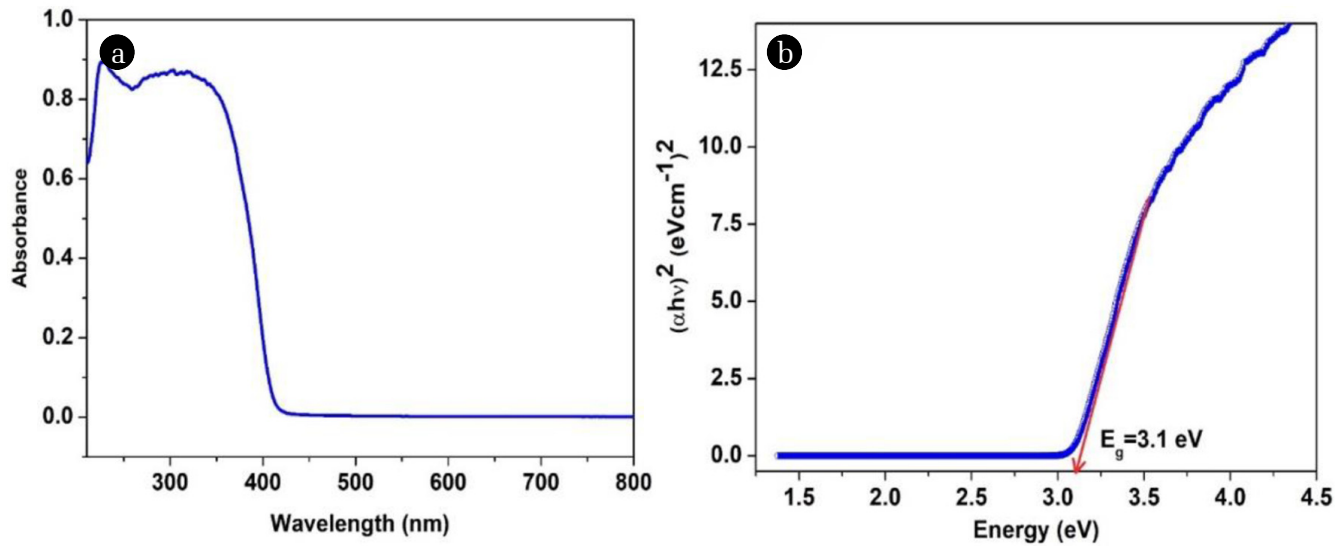

Fig. 3. (a) UV-Vis spectrum and (b) optical band gap of sol gel derived $\mathrm{TiO}_{2}$. 


\subsection{Effect of Catalysts Dosage}

To detect the effect of catalyst dosage, the repeated experiments were conducted under UV light. The amount of the $\mathrm{TiO}_{2}$ catalyst ranging from 1 to $6 \mathrm{mg}$ at constant dye volume $(10 \mathrm{~mL}$ solution of $10 \mathrm{ppm}$ ) at natural $\mathrm{pH}$ (5.16) with mixing speed of $300 \pm 10$ rpm has been taken. Initial and final concentrations of dye have been determined by using UV/visible spectrometer. From Fig. 4(a) it can be seen that as the amount of catalyst increased the percentage of dye degradation also increased. The increase is found up to $3 \mathrm{mg}$ beyond which there is little degradation. This can be attributed to the increased active sites of the catalyst with a high dosage. However, further increased dosage of the catalyst did not show effective degradation. The reasons are, the deposition of dye on the catalyst and the dye decomposition rate by the catalyst are influenced by several active sites and the absorption of photons by the catalysts $[20,21]$. High catalyst loading enhances the rate of generation of electron-hole pairs and thereby increases the degradation rate. However, the addition of high dosage decreases the penetration of light by photocatalysts suspension. High catalyst dosage can also not affect degradation rate because of a smaller number of dye molecules to react.

\subsection{Effect of Time}

Fig. 4(b) illustrating the effect of contact time on the degradation of $\mathrm{MG}$ dye by $\mathrm{TiO}_{2}$. The experiments were conducted under UV light at different contact time intervals (10 min to $100 \mathrm{~min}$ at the step size of 10) by keeping catalyst amount constant, dye concentration and $\mathrm{pH}$ constant. As time increased the percentage of dye degradation also increased to the maximum extent, after that it remains almost constant. This is because, as time increases the contact time between the molecules of dye and catalysts also increases which enhances the degradation rate. The availability of active sites of the catalyst will be initially more for the dye molecules to react; after some time, the catalyst surface becomes saturated due to the deposition of more and more dye molecules. So, the increased time shows no effect on dye degradation [22].

\subsection{Effect of Initial Dye Concentration}

Fig. 4(c) shows the influence of different dye concentration on the percentage dye degradation. The experiments were conducted under UV light at different initial dye concentration (10 ppm to $50 \mathrm{ppm}$ at the interval of $10 \mathrm{ppm}$ ) by keeping other parameters constant. From Fig. 4(c) it is clear that the increased initial dye concentration decreased the rate of dye degradation. Increased dye concentration enhances the colour intensity and thereby screens the light penetration into the solution, which leads to the less availability of photons for the degradation reaction. Another reason is that some of the photons were absorbed by the many molecules of MG dye itself and thereby reduces the availability of photons to the catalyst surface. This leads to the reduction in the amount of excited $\mathrm{TiO}_{2}$ and holes also. So lesser number of holes enters the dye solution and reacts with the hydroxide ions and gives hydroxyl radicals, the primary and vital reactive oxygen species for the photo-oxidation of dye molecules [23].

\section{Mathematical Function using Design of Experiments and Response Surface Method}

The experimental data were analysed using multiple regression (statistical method) in order to find the relationship between the factors and response variables. The obtained response values produced by BBD were fitted in different models such as linear, square, 2-way interaction. The regression Eq. (5) obtained is as follows:

$$
\begin{aligned}
\mathrm{Y}= & 61.53700+1.75455 \mathrm{x}_{1}-0.03628 \mathrm{x}_{1}^{2}-8.53725 \mathrm{x}_{2}+ \\
& 2.65950 \mathrm{x}_{2}^{2}+0.06474 \mathrm{x}_{3}+0.00521 \mathrm{x}_{3}^{2}+ \\
& 0.01730 \mathrm{x}_{1} \mathrm{x}_{2}-0.01098 \mathrm{x}_{1} \mathrm{x}_{3}-0.01292 \mathrm{x}_{2} \mathrm{x}_{3}
\end{aligned}
$$

The linear terms of $\mathrm{x}_{1}, \mathrm{x}_{3}$ showed positive values and also shown a synergistic effect on the response, $x_{2}$ is negative value while the squared term $\mathrm{x}_{1}{ }^{2}$ shows the negative value and antagonistic effect, while $\mathrm{x}_{2}{ }^{2}, \mathrm{x}_{3}{ }^{2}$ are positive values. The interaction terms $\mathrm{x}_{1} \mathrm{x}_{3}, \mathrm{x}_{2} \mathrm{x}_{3}$ were found to have an adverse effect on the response, whereas the interaction effect of $\mathrm{x}_{1} \mathrm{x}_{2}$ was positive.

Analysis of variance (ANOVA) results suggest that the model was of significant importance (Table 1) as per F-test with the low p- values $<0.05$, and significant $\mathrm{R}^{2}$ value 0.95322 . The experimental and the prediction of response values are also connecting, as shown in Table 2, which confirms statistical validation of experimental data.
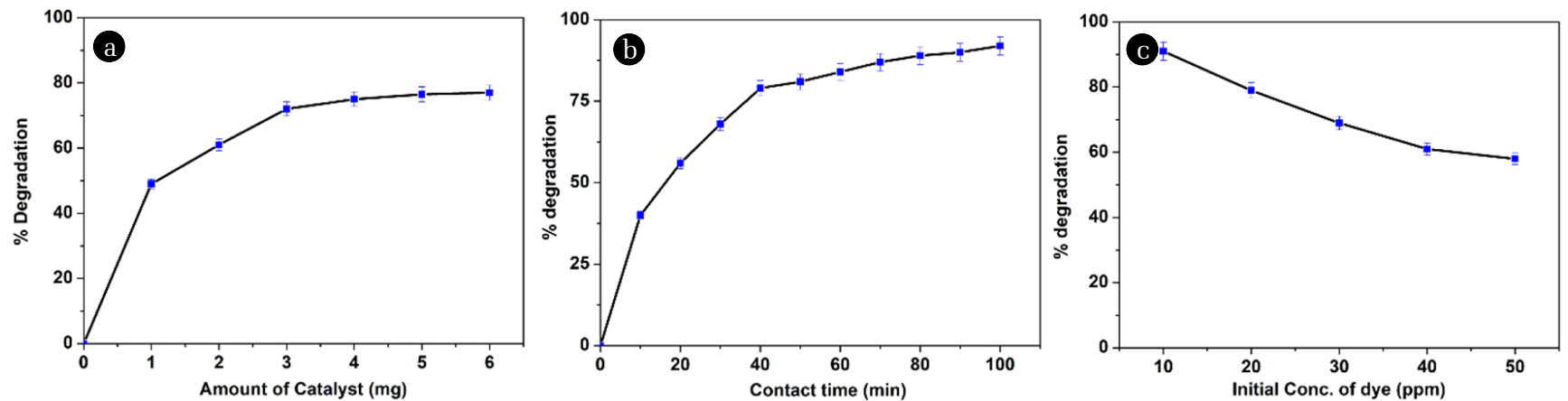

Fig. 4. Effect of (a) catalyst dose (b) contact time (c) initial dye concentration on degradation of Malachite degradation in presence of $\mathrm{TiO}_{2}$ catalyst. 
Table 1. Analysis of Variance (ANOVA)

\begin{tabular}{lccccc}
\hline Source of variations & Some of Squares & DOF & Mean Square & F-test & P-value \\
\hline$\left(\mathrm{x}_{1}\right)$ Initial Concentration (ppm) L + Q & 60.9140 & 2 & 30.45699 & 11.13682 & 0.009557 \\
$\left(\mathrm{x}_{2}\right)$ Catalyst Dosage (mg) L + Q & 58.0832 & 2 & 29.04162 & 10.61929 & 0.010688 \\
$\left(\mathrm{x}_{3}\right)$ Contact Time (min) L + Q & 195.6561 & 2 & 97.82803 & 35.77155 & 0.000463 \\
$\mathrm{x}_{1}{ }^{*} \mathrm{x}_{2}$ Interactions & 0.1197 & 1 & 0.11972 & 0.04378 & 0.841195 \\
$\mathrm{x}_{1}{ }^{*} \mathrm{X}_{3}$ Interactions & 19.2984 & 1 & 19.29845 & 7.05662 & 0.037703 \\
$\mathrm{x}_{2}{ }^{*} \mathrm{X}_{3}$ Interactions & 0.2673 & 1 & 0.26729 & 0.09774 \\
Error & 16.4088 & 6 & 2.73480 & 0.765144 \\
Total SS & 350.7475 & 15 & & & \\
\hline
\end{tabular}

ANOVA; Var.: Degradation (\%); R-sqr =.95322; Adj:.88304, Three 3-level factors, 1 Blocks, 16 Runs; MS Residual = 2.7348 DV: Degradation (\%)

Table 2. Box Behnken Experimental Designs, Effect of Initial Concentration, $\mathrm{TiO}_{2}$ Dosage and Time

\begin{tabular}{|c|c|c|c|c|c|c|}
\hline & \multirow{2}{*}{$\begin{array}{l}\text { Initial Concentration (ppm), } \\
\mathrm{X}_{1}\end{array}$} & \multirow{2}{*}{$\begin{array}{l}\text { Catalyst Dosage (mg), } \\
\qquad \mathrm{X}_{2}\end{array}$} & \multirow{2}{*}{$\begin{array}{c}\text { Time (min), } \\
\mathbf{X}_{3}\end{array}$} & Experimental & Predicted (RSM) & Predicted (ANN) \\
\hline & & & & \multicolumn{3}{|c|}{ \% Degradation } \\
\hline 1 & 10.00000 & 1.000000 & 40.00000 & 76.120 & 75.76475 & 76.12 \\
\hline 2 & 30.00000 & 1.000000 & 40.00000 & 74.101 & 73.38775 & 69.93 \\
\hline 3 & 10.00000 & 3.000000 & 40.00000 & 78.565 & 79.27825 & 78.57 \\
\hline 4 & 30.00000 & 3.000000 & 40.00000 & 77.238 & 77.59325 & 77.24 \\
\hline 5 & 10.00000 & 2.000000 & 20.00000 & 69.017 & 70.02875 & 69.02 \\
\hline 6 & 30.00000 & 2.000000 & 20.00000 & 71.021 & 72.39075 & 71.02 \\
\hline 7 & 10.00000 & 2.000000 & 60.00000 & 85.233 & 83.86325 & 85.23 \\
\hline 8 & 30.00000 & 2.000000 & 60.00000 & 78.451 & 77.43925 & 78.45 \\
\hline 9 & 20.00000 & 1.000000 & 20.00000 & 75.966 & 75.30950 & 75.97 \\
\hline 10 & 20.00000 & 3.000000 & 20.00000 & 81.411 & 79.68600 & 81.41 \\
\hline 11 & 20.00000 & 1.000000 & 60.00000 & 83.543 & 85.26800 & 86.3 \\
\hline 12 & 20.00000 & 3.000000 & 60.00000 & 87.954 & 88.61050 & 87.95 \\
\hline 13 & 20.00000 & 2.000000 & 40.00000 & 77.744 & 77.47500 & 78.2 \\
\hline 14 & 20.00000 & 2.000000 & 40.00000 & 78.658 & 77.47500 & 78.2 \\
\hline 15 & 20.00000 & 2.000000 & 40.00000 & 76.749 & 77.47500 & 78.2 \\
\hline
\end{tabular}

\subsection{Interactive Effects of Initial Dye Concentration and Catalyst Dosage}

Fig. 5(a), (b) and (c) represents contour plots to verify the combined effects of two factors by keeping other factors as constant. Fig 5(a) shows the effect of initial dye concentration and catalyst dosage on \% degradation. The degradation percentage increases as an increase in the dosage of the catalyst at optimal initial dye concentration around 20 ppm, as shown in Fig. 5(a). This can be attributed to the increased number of available dye molecules to react with catalyst. However, after optimum value $(20 \mathrm{ppm})$ the increased dye concentration leads to the increase in the intensity of molecules which covers the outer surface of the reaction mixture and thereby scatters the light which in turn decreases the penetration of the sufficient photons into the solution, which leads to the decrease in the dye degradation rate [24].

Similarly, as the amount of catalyst increases the number of active sites over the catalyst surface available for the dye molecules to react increases and hence enhances the degradation rate. After optimum range ( $3 \mathrm{mg}$ ) in the Fig. 5(a), the catalyst molecules aggregate themselves and thereby shields the photons penetration to reach the dye molecules. This leads to less interaction between the molecules of the dye and active sites of catalyst surfaces [25].

\subsection{Interactive Effect of Contact Time and Initial Dye Concentration}

Fig. 5(b) represents the effect of irradiation time and initial dye concentration on percentage dye degradation. At $20 \mathrm{ppm}$ of initial dye concentration, the percentage of dye degradation is also increasing as time increases. the dye degradation increased by extending the time up to $60 \mathrm{~min}$ this is because as the irradiation time increases, the number of photons absorbed by the catalyst surface increases, this, in turn, enhances the reactive oxygen species responsible for photodegradation and hence leads to more significant dye degradation [26]. Besides, the available time for the interaction between 
Desirability Surface/ Contours; Method: Spline Fit
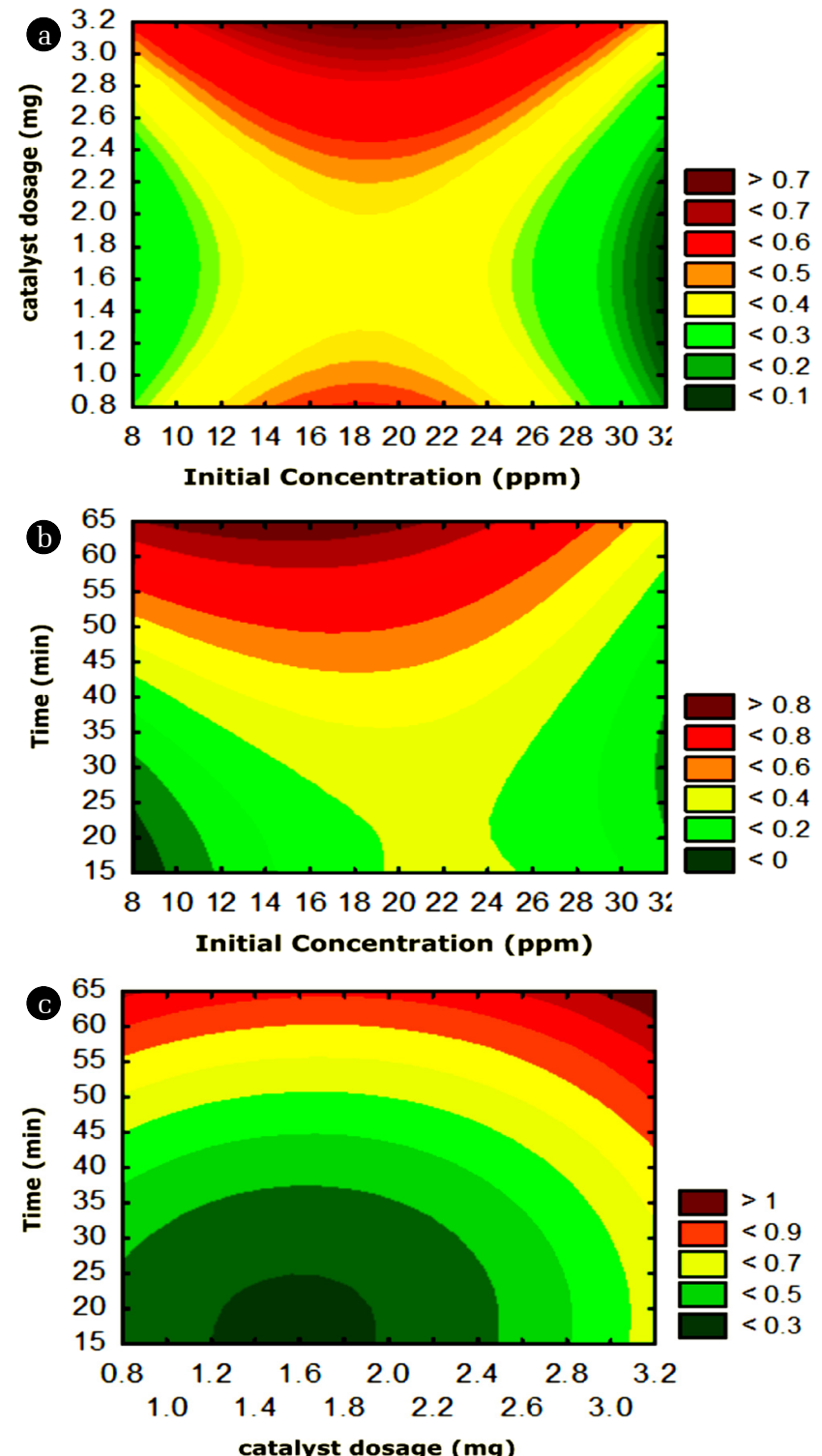

Fig. 5. Contour plots of degradation against (a) dye $\mathrm{v} / \mathrm{s}$ dosage (b) dye $\mathrm{v} / \mathrm{s}$ time (c) dosage $\mathrm{v} / \mathrm{s}$ time.

the dye molecules and the active oxygen species over the catalyst surface increases leads to more significant degradation. Suppose the initial dye concentration crosses some optimal range $20 \mathrm{ppm}$ in the Fig. 5(b) the degradation rate decreases even as the time increases. In that case, this is because the increased dye concentration enhances the colour intensity and there by shields the light penetration into the solution and the less availability of photons for the degradation to occur.

\subsection{Interactive Effects of Contact Time and Catalyst Dosage}

Fig. 5(c) represents the influence of irradiation time and catalyst dosage on percentage dye degradation. The highest percentage of dye degradation was observed at the catalyst amount of $3 \mathrm{mg}$ in Fig 5(c). It can be attributed to the increased number of active sites on the $\mathrm{TiO}_{2}$ surface, which increases the highly reactive oxygen species like hydroxide and superoxide radicals and hence more degradation. After a certain amount (saturation amount), the available dye molecules are insufficient to fill all the active sites of the catalyst. Besides, more amount of the catalyst leads to the particles aggregation and thereby leads to the light scattering, which reduces the number of available photons for the photodegradation, hence lesser dye degradation [27]. The irradiation time is another crucial factor which influences the photodegradation, as the irradiation time increases the number of photons available for the reaction increases. Another reason is that, the increased time increases the interaction time required for the dye molecules, and the catalyst molecules increases and hence enhances the reaction. After an optimum time, it does not affect photodegradation reaction because all the active sites of the catalyst surface become saturated due to the deposition of a more significant number of dye molecules. Hence further increase in time does not affect dye degradation [28].

This analysis showed that BBD could optimize the process of degradation; however, further to improve the data obtained from the second-order polynomial Eq. (5) obtained from BBD, RSM and the ANN have been used.

\section{ANN Approach}

Further modeling and optimization of data which is generated by second order polynomial Eq. (5) was done by using ANN and DIRECT Algorithm [19] to determine the better multiple coefficients. the details such as Input layer, two Hidden layers (6 neurons in each layers), and output layer of ANN shown in Fig. 6. Ravi et al. [19] have suggested Eq. (6), which was used for computation of weights and bias using neural network. The weights and bias are used for optimization using DIRECT Algorithm suggested by Jones et al. [29], at maximum $\mathrm{R}^{2}$ value.

$$
Y=w_{2} *\left(\left[\frac{2}{1+e^{\frac{-2}{w_{1}^{*} x v_{1}+b_{1}}}}\right]-1\right)+b_{2}
$$

The above equation was used into DIRECT algorithm for optimization [30]. Here weights are represented as $\mathrm{w}_{1}$ and $\mathrm{w}_{2}$, biases as $b_{1}$ and $b_{2}$. The predicted value from the neural network as ' $\mathrm{y}$ ', row vector $\mathrm{xv}_{1}$ represent the transpose of the vector with a dimension of $\left(3 \mathrm{x}_{1}\right)$.

The experimental and predicted values are listed in Table 2. When compared the values generated from the ANN model with the BBD, the predicted number of values from ANN model are closer to the experimental values than BBD. The comparison of the predicted values of $\mathrm{BBD}$ and $\mathrm{ANN}$ with the regression line can be seen in Fig. 7. It is clear that the ANN is a more efficient model and precisely estimated the experimental values. Similar studies in literature also proved the better performance of ANN when compared with BBD approach using RSM [30]. According to the $\mathrm{BBD}$, the maximum achievable percentage degradation is $88.61\left(\mathrm{R}^{2}\right.$ value 0.95322$)$ and with further optimization using 


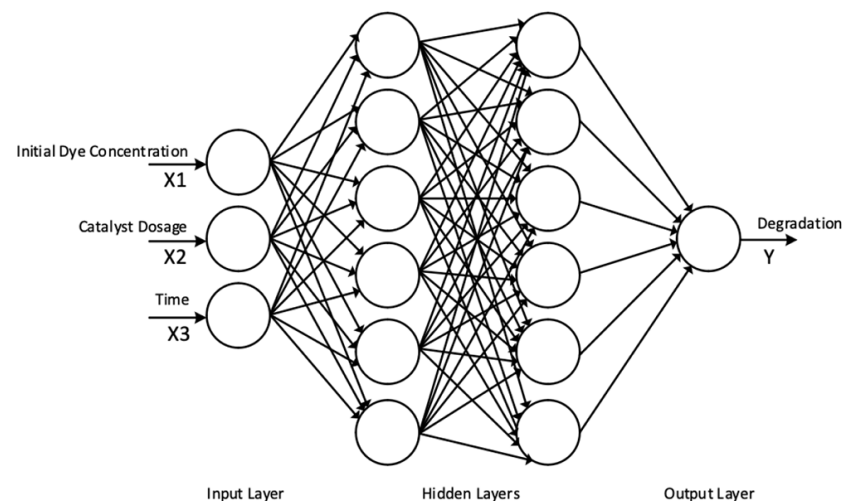

Fig. 6. ANN topology $(3: 6: 1)$.

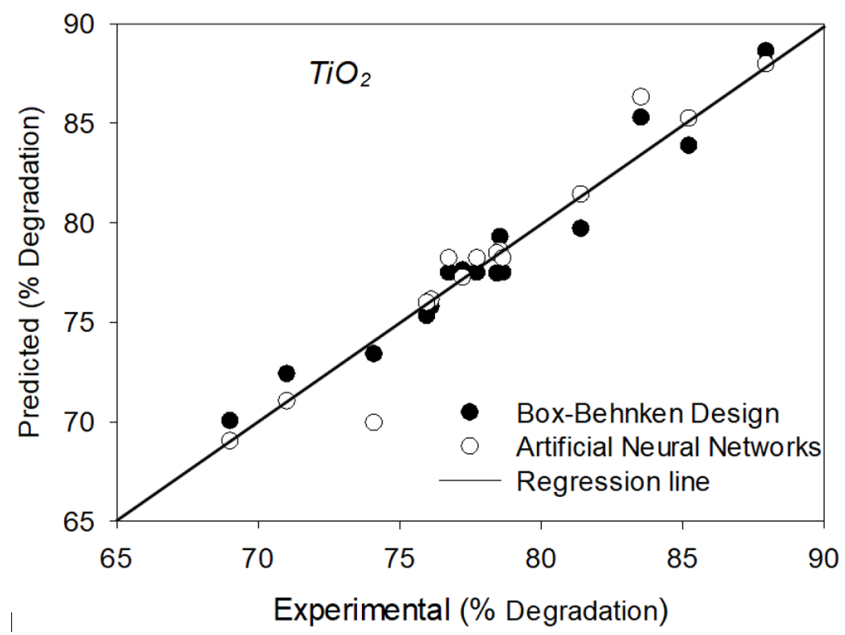

Fig. 7. Comparison of BBD, ANN with Regression line.

ANN and DIRECT algorithm [29] the optimal value yield from ANN found to be $88.8622\left(\mathrm{R}^{2}\right.$ value 0.97073 ) for maximum dye degradation. As a part of testing the model, we conducted experiments at the final optimized conditions; we could able to achieve $89 \%$ dye degradation. The difference of optimum value predicted from optimum conditions of ANN (using Eq. (6)) and the computed optimum value from the RSM for optimum parameters of ANN is 0.1378 which is less than the error values from the repeatability of the experiment, hence the validity of the model.

\section{Conclusions}

In summary, the work demonstrates the potential use of $\mathrm{TiO}_{2}$ as photocatalyst for the degradation of Malachite green dye. The powder X-ray diffraction studies showed that the sol-gel derived nano $\mathrm{TiO}_{2}$ resulted in Anatase phase without impurities. Scanning electron micrographs and Transmission electron microscopic images revealed an agglomerated cluster of particles and nano size of the $\mathrm{TiO}_{2}$. RSM was effectively carried out for the optimization of photocatalytic experimental parameters based on BBD model and ANN model. Statistical based analysis using Box-Behnken methodology and the ANN model proposed successfully predicted the malachite green dye degradation using $\mathrm{TiO}_{2}$ as photocatalyst. The optimum parameters for the maximum degradation efficiency (90\%) were found to be $\mathrm{TiO}_{2}$ nanoparticle dosage $3 \mathrm{mg}$; reaction time $60 \mathrm{~min}$; and under the exposer to UV light irradiation for $20 \mathrm{ppm}$ of initial dye concentration. The predicted values form the BBD and ANN models excellently matched with these values. Hence, these results show that the optimization using Box-Behnken approach and ANN approach are excellent tools for evaluating the optimal conditions for pollutant degradation and in this case, ANN model was found to be superior to BBD model.

\section{Author Contributions}

C.K.C. (Ph.D. student) conducted all experimental work and prepared original manuscript draft, T.N.P. (Professor) supervised the research, initial plan and revised the manuscript, R.R.S.K. (Assistant professor) contributed in conceptualization and revision. R.H.K. (Assistant professor) contributed in analysis, writing and revision of manuscript.

\section{Reference}

1. Kumar A, Chaturvedi AK, Yadav K, et al. Fungal phytoremediation of heavy metal-contaminated resources: current scenario and future prospects. In: Yadav A, Singh S, Mishra S, Gupta A, eds. Recent Advancement in White Biotechnology Through Fungi. Fungal Biology. Springer, Cham; 2019. p. 437-461.

2. Borker P, Salker AV. Photocatalytic degradation of textile azo dye over $\mathrm{Ce}_{1-\mathrm{x}} \mathrm{Sn}_{\mathrm{x}} \mathrm{O}_{2}$ series. Mater. Sci. Eng. $B$ 2006;133:55-60.

3. Srivastava S, Sinha R, Roy D. Toxicological effects of malachite green. Aquat. Toxicol. 2004;66(3):319-329.

4. Hoffmann MR, Martin ST, Choi W, Bahnemann DW. Environmental applications of semiconductor photocatalysis. Chem. Rev. 1995;95(1):69-96.

5. Muhd JN, Bagheri S, Bee AHS. Recent advances in heterogeneous photocatalytic decolorization of synthetic dyes. Sci. World J. 2014;2014:1-25.

6. Jang YJ, Simer C, Ohm T. Comparison of zinc oxide nanoparticles and its nano-crystaline particles on the photocatalytic degradation of methylene blue. Mater. Res. Bull. 2006;41(1):67-77.

7. Marci G, Augugliaro V, Lopez-Munoz MJ, et al. Preparation characterization and photocatalytic activity of polycrystalline $\mathrm{ZnO} / \mathrm{TiO}_{2}$ systems surface, bulk characterization, and 4-nitrophenol photodegradation in liquid-solid regime. J. Phys. Chem. B. 2001;105(5):1033-1040.

8. Mathur S, Barth S. Molecule-Based Chemical Vapor Growth of Aligned $\mathrm{SnO}_{2}$ Nanowires and Branched $\mathrm{SnO}_{2} / \mathrm{V}_{2} \mathrm{O}_{5}$ Heterostructures. Small 2007;3(12):2070-2075.

9. Zheng L, Zheng Y, Chen $\mathrm{C}$, et al. Network structured $\mathrm{SnO}_{2} / \mathrm{ZnO}$ heterojunction nanocatalyst with high photocatalytic activity. Inorg. Chem. 2009;48(5):1819-1825.

10. Pirdashti M, Curteanu S, Kamangar MH, Hassim MH, Khatami MA. Artificial neural networks: applications in chemical engineering. Rev. Chem. Eng. 2013;29(4):205-239. 
11. Sumpter BG, Getino C, Noid DW. Theory and applications of neural computing in chemical science. Annu. Rev. Phys. Chem. 1994;45(1):439-481.

12. Pigram GM, MacDonald TR. Use of neural network models to predict industrial bioreactor effluent quality. Environ. Sci. Technol. 2001;35(1):157-162.

13. Miller JN. Basic statistical methods for analytical chemistry. Part 2. Calibration and regression methods. A review. Analyst 1991;116(1):3-14.

14. Elmolla ES, Chaudhuri M. The use of artificial neural network (ANN) for modelling, simulation and prediction of advanced oxidation process performance in recalcitrant wastewater treatment. Dr. Chi Leung Patrick Hui ed. IntechOpen; 2011. p. $105-124$.

15. Mohammadi R, Eskandarloo H, Mohammadi M. Application of artificial neural network (ANN) for modeling of dyes decolorization by $\mathrm{Sn} / \mathrm{Zn}-\mathrm{TiO}_{2}$ nanoparticles. Desalination Water Treat. 2015;55(7):1922-1933.

16. Osouleddini N, Heydari M, Motevalli MD, Khosravi T. Application of artificial neural networks and response surface methodology for analysis of malachite green removal from aqueous solution using phosphoric acid-modified pumice powder: kinetic and isotherm studies. Desalin. Water Treat. 2020;178: 296-311.

17. Maran JP, Manikandan S, Mekala V. Modeling and optimization of betalain extraction from Opuntia ficus-indica using BoxBehnken design with desirability function. Ind. Crops Prod. 2013;49:304-311.

18. Nagata Y, Chu KH. Optimization of a fermentation medium using neural networks and genetic algorithms. Biotechnol. Lett. 2003;24(21):1837-1842.

19. Dasari VRRK, Donthireddy SRR, Nikku MY, Garapati HR. Optimization of medium constituents for Cephalosporin C production using response surface methodology and artificial neural networks. J. Biochem. Technol. 2009;1(3):69-74.

20. Akyol A, Yatmaz HC, Bayramoglu M. Photocatalytic decolorization of Remazol Red RR in aqueous $\mathrm{ZnO}$ suspensions. Appl.
Catal. B: Environmental. 2004;54(1):19-24.

21. Byrappa K, Subramani AK, Ananda S, Rai KL, Dinesh R, Yoshimura M. Photocatalytic degradation of rhodamine B dye using hydrothermally synthesized ZnO. Bull. Mater. Sci. 2006;29(5):433-438.

22. Chaibakhsh N, Ahmadi N, Zanjanchi MA. Optimization of photocatalytic degradation of neutral red dye using $\mathrm{TiO}_{2}$ nanocatalyst via Box-Behnken design. Desalin. Water Treat. 2016 57(20):9296-9306.

23. Malik PK, Saha SK. Oxidation of direct dyes with hydrogen peroxide using ferrous ion as catalyst. Sep. Purif. Technol. 2003;31(3):241-250.

24. YasiniArdakani S, Abghari R, Mirjalili M. $\mathrm{TiO}_{2} @ \mathrm{CoFe}_{2} \mathrm{O}_{4}$ Nanofiber for the Photocatalytic Degradation of Direct Red 80. Phys. Chem. Res. 2019;7(2):309-325.

25. Mohamed FF, Allah PM, Mehdi AP, Baseem M. Photo removal of Malachite Green (MG) using advanced oxidation process. Res. J. Chem. Environ. 2011;15(3):65-70.

26. Aisien FA, Blessing A. Photocatalytic degradation of 2, 2, 4 trimethyl pentane (isooctane) in aqueous solution. Iran. $J$. Neonatol. 2014;4(4):1-7.

27. Giwa A, Nkeonye PO, Bello KA, Kolawole KA. Photocatalytic decolorization and degradation of $\mathrm{Cl}$ Basic Blue 41 using $\mathrm{TiO}_{2}$ nano particles. J. Environ. Prot. Ecol. 2012;3(9):1063-1069.

28. Talebi S, Chaibakhsh N, Moradi-Shoeili Z. Application of nanoscale $\mathrm{ZnS} / \mathrm{TiO}_{2}$ composite for optimized photocatalytic decolorization of a textile dye. J. Appl. Res. Technol. 2017;15(4): 378-385.

29. Jones DR, Perttunen CD, Stuckman BE. Lipschitzian optimization without the Lipschitz constant. J. Optim. Theory Appl. 1993;79(1):157-181.

30. Kiran RS, Madhu GM, Satyanarayana SV, Kalpana P, Rangaiah GS. Applications of Box-Behnken experimental design coupled with artificial neural networks for biosorption of low concentrations of cadmium using Spirulina (Arthrospira) spp. Resour Efficient Technol. 2017;3(1):113-123. 